\title{
Sesamin inhibits lipopolysaccharide-induced proliferation and invasion through the p38-MAPK and NF-kB signaling pathways in prostate cancer cells
}

\author{
PEIYUAN XU, FEI CAI, XIAOFEI LIU and LELE GUO \\ Department of Urology, The First Affiliated Hospital of Zhengzhou University, Zhengzhou, Henan 450052, P.R. China
}

Received December 5, 2014; Accepted March 5, 2015

DOI: $10.3892 /$ or.2015.3888

\begin{abstract}
Sesamin, a lipid-soluble lignan, is one of the major constituents of sesame. Previous studies have reported that sesamin induces growth inhibition in human cancer cells, particularly prostate cancer cells. In the present study, we mainly explored the mechanism underlying the protective effect of sesamin on prostate cancer cell proliferation and invasion induced by lipopolysaccharide (LPS). We found that the proliferation of PC 3 cells, as determined using the MTT assay, and the expression of cyclin D1, COX-2, Bcl-2 and survivin proteins elevated by LPS were distinctly inhibited by sesamin in a dosedependent manner. Meanwhile, the ability of PC 3 cell invasion, as determined using the Transwell assay and the expression of matrix metalloproteinase 9 (MMP-9), intercellular adhesion molecule-1 (ICAM-1) and vascular endothelial growth factor (VEGF) proteins increased by LPS were obviously reduced by sesamin in a dose-dependent manner. In addition, the accumulation of TGF- $\alpha$ and interleukin-6 (IL-6) production induced by LPS in the culture supernatant was found to be decreased dose-dependently with sesamin pretreatment in PC3 cells using the enzyme-linked immunosorbent assay (ELISA) kit. Furthermore, phosphorylation of the $\mathrm{p} 38$ protein and nuclear factor (NF)- $\kappa \mathrm{B}$ activity in the PC3 cells were enhanced by LPS and further inhibited with sesamin, SB203580 pretreat-
\end{abstract}

Correspondence to: Dr Peiyuan Xu, Department of Urology, The First Affiliated Hospital of Zhengzhou University, No. 1 Jianshedong Road, Zhengzhou, Henan 450052, P.R. China

E-mail: peiyuan_xu@126.com

Abbreviations: LPS, lipopolysaccharide; NF- $\kappa \mathrm{B}$, nuclear factor $\kappa \mathrm{B}$; p38-MAPK, p38 mitogen-activated protein kinase; TNF- $\alpha$, tumor necrosis factor- $\alpha$; IL-6, interleukin-6; EMT, epithelial-mesenchymal transition; BCA, bicinchoninic acid; FBS, fetal bovine serum; ATCC, American Type Culture Collection; SDS-PAGE, sodium dodecylsulphate polyacrylamide gel electrophoresis; RIPA, radioimmunoprecipitation assay; ECL, enhanced chemiluminescence; VEGF, vascular endothelial growth factor; ICAM-1, intercellular adhesion molecule-1; MMP-9, matrix metalloproteinase 9; ELISA, enzymelinked immunosorbent assay; MTT, 3-(4,5-dimethylthiazol-2-yl)-2,5diphenyltetrazolium bromide

Key words: sesamin, LPS, prostate cancer, proliferation, invasion ment or p38-siRNA transfection, respectively. Sesamin or SB203580 pretreatment obviously inhibited PC3 cells-derived tumor growth induced by LPS in vivo. Taken together, these results suggest that the potential ability of sesamin to downregulate the secretion of cytokines and the expression of cell proliferative- and invasive-related gene products induced by LPS was shown to be via the p38 mitogen-activated protein kinase (p38-MAPK) and NF- $\mathrm{B}$ signaling pathways, which may be one of the mechanisms of the anticancer activity of this sesamin agent in prostate cancer cells.

\section{Introduction}

Prostate cancer is the second most commonly diagnosed cancer among Chinese-American males, contributing to the overall cancer burden in this population (1-3). Large increases in both the incidence and mortality rates of prostate cancer are noted for all countries including low-risk populations, but substantial differences exist between countries. According to previous research, genetic, dietary, lifestyle and environmental factors are considered to play an influential role in the etiology of prostate cancer development $(2,4)$.

Lipopolysaccharide (LPS) is a representative strong stimulator of inflammation and has been demonstrated to be associated with various steps in chronic inflammation, such as altering cytokine levels by stimulating inflammatory cells in the tumor microenvironment (5). LPS exposure can also lead to carcinogenesis, induce tumor cell proliferation and survival, facilitate invasion and metastasis, and promote angiogenesis (6-8). For example, LPS can promote prostate cancer PC3 cell migration (9) by inducing the secretion of tumor necrosis factor- $\alpha$ (TNF- $\alpha$ ) and interleukin-6 (IL-6) (10), serum levels of which are correlated with the extent of disease in patients with prostate cancer (11). TNF- $\alpha$ has been frequently detected in biopsies from ovarian, renal and breast cancer $(12,13)$ and IL-6 also exhibits a strong association with many types of cancer (14-18). Moreover, research suggests that LPS plays an accelerative role in mediating epithelial-mesenchymal transition (EMT), which has been proposed as a key process in cancer progression with increased migration and invasiveness (19), by modifying the nuclear factor (NK)- $\kappa \mathrm{B}$ signaling pathway in breast cancer cells (20). Hence, we speculated that LPS may promote prostate cancer cell proliferation and invasion and tumor progression. 
The effect of dietary-derived inhibitory factors on cancer cell invasion and progression have been investigated, such as curcumin (20), anthocyanins from fruits of Vitis coignetiae Pulliat (21), green tea polyphenols (22), and lycopene and $\beta$-carotene from fruits and vegetables (23). Sesamin, a lignan component from sesame oil, is considered as a common but healthy food with antihypertensive and antioxidative activities. According to previous studies, the potential anticancer effects of food-derived sesamin on human cancer, including breast and colon cancer, hepatocellular carcinoma, and lung cancer are well documented (24-28).

Moreover, sesamin plays an inhibitory role in human prostate cancer cell proliferation (29), implying its potential anticancer application. However, the nature of the growth inhibitory mechanism remains unknown, and the effect of sesamin on prostate cancer cell invasion stimulated by LPS also remains unclear. In the present study, we mainly explored the protective effect of sesamin on the development of prostate cancer cell invasion and tumor progression induced by LPS.

\section{Materials and methods}

Mouse treatment and cell culture. Male BALB/c nude mice, aged 6-8 weeks (20 $\pm 2 \mathrm{~g})$, were purchased from Belda Biomedical Science and Technology Co., Ltd. (Suzhou, China). The mice were maintained and used in strict accordance with international standards of animal care guidelines. All experimental procedures were carried out in accordance with the regulations of the Zhengzhou University Committee on Ethics in the Care and Use of Laboratory Animals and were approved by the University Committee for Animal Experiments.

Human prostate cancer cell line PC3 was purchased from the American Type Culture Collection (ATCC; Manassas, VA, USA). PC3 cells were maintained in RPMI-1640 medium supplemented with $10 \%$ heat-inactivated fetal bovine serum (FBS) (both from Gibco, Rockville, MD, USA), $100 \mathrm{U} / \mathrm{ml}$ penicillin, and $100 \mu \mathrm{g} / \mathrm{ml}$ streptomycin (Life Technologies, Rockville, MD, USA), in a humidified atmosphere of 5\% $\mathrm{CO}_{2}-95 \%$ air at $37^{\circ} \mathrm{C}$. Sesamin was dissolved initially in dimethyl sulfoxide (DMSO), stored as small aliquots at $-20^{\circ} \mathrm{C}$, then thawed and diluted in a cell culture medium as required to a final concentration of $0,10,50$ or $100 \mu \mathrm{g} / \mathrm{ml}$.

MTT assay. PC3 cells were seeded into 96-well plates (Corning Inc., Corning, NY, USA) at a density of $5 \times 10^{3}$ cells/well in RPMI-1640 medium with 10\% FBS. After $24 \mathrm{~h}$, the cells were pre-incubated with 0,10 (S10), 50 (S50) or 100 (S100) $\mu \mathrm{g} / \mathrm{ml}$ of sesamin, for $1 \mathrm{~h}$ before treatment with $1 \mu \mathrm{g} / \mathrm{ml}$ of LPS (both from Sigma-Aldrich, St Louis, MO, USA) at $37^{\circ} \mathrm{C}$ in $5 \%$ of $\mathrm{CO}_{2}$. Next, 24 or $48 \mathrm{~h}$ later, $20 \mu \mathrm{l}$ of modified tetrazolium salt 3-(4,5-dimethyl-2-thiazolyl)-2,5-dipheny$2 \mathrm{H}$-tetrazolium-bromide (MTT, $5 \mathrm{mg} / \mathrm{ml}$; Sigma-Aldrich) was added to each well and samples were incubated at $37^{\circ} \mathrm{C}$ for $4 \mathrm{~h}$. Then the supernatant was carefully removed and $100 \mu \mathrm{l}$ of DMSO (Sigma-Aldrich) was added to lyse the cells. After the dark-blue MTT crystals dissolved, the absorbance was measured at $490 \mathrm{~nm}$ using a Benchmark microplate reader (Bio-Rad, Hercules, CA, USA).
Invasion assay. In regards to the Transwell system, Matrigel-coated 24-well Transwell chambers with 8.0- $\mu \mathrm{m}$ polycarbonated filters (Corning Inc.) were used for the in vitro invasion assay. Here, $1 \times 10^{5}$ cells $/ 300 \mu 1$ were suspended in serum-free RPMI-1640 medium in the upper chamber of each well, and the lower well of each chamber was filled with $750 \mu 1$ RPMI-1640 medium supplemented with $15 \%$ of FBS. LPS $(1 \mu \mathrm{g} / \mathrm{ml})$ and sesamin $(0,10,50$ and $100 \mu \mathrm{g} / \mathrm{ml})$ were added to both the upper and the lower chambers as described above. After $24 \mathrm{~h}$ of treatment, the filters were fixed with $4 \%$ paraformaldehyde and stained with $0.1 \%$ crystal violet (both from Sigma-Aldrich). Then, the number of invasive cells in at least five randomly selected microscope fields was counted and analyzed statistically.

Cytokine assay. PC3 cells were cultured in 6-well plates (Corning Inc.) at a density of $4 \times 10^{5}$ cells/well in RPMI-1640 medium. LPS $(1 \mu \mathrm{g} / \mathrm{ml})$ and sesamin $(0,10,50$ and $100 \mu \mathrm{g} / \mathrm{ml})$ were added as described previously. Conditioned medium was collected over 48 h. Cytokines, including TNF- $\alpha$ and IL-6, contained in the conditioned medium were analyzed in triplicate using a sandwich-type enzyme-linked immunosorbent assay (ELISA) kit (R\&D Systems, Minneapolis, MN, USA) according to the manufacturer's instructions. The absorbance at $450 \mathrm{~nm}$ was determined using a microplate reader (Bio-Rad).

p38-siRNA transfection. For siRNA transfection, PC3 cells were seeded in 6 -well plates at a density of $4 \times 10^{5}$ cells/ well and transfected on the following day with p38-siRNA (25 nM; Cell Signaling Technology, Beverly, MA, USA) or the non-silencing control siRNA (si-NS, $25 \mathrm{nM}$ ), as indicated using Lipofectamine 2000 (both from Invitrogen, Carlsbad, CA, USA), according to the manufacturer's instructions. The transfection efficiency of p38-siRNA was determined by western blotting.

Western blot analysis. Cultured PC3 cells were extracted using radioimmunoprecipitation assay (RIPA) lysis buffer (Beyotime, Shanghai, China) after transfection and stimulation of LPS $(1 \mu \mathrm{g} / \mathrm{ml})$ and sesamin $(0,10,50$ and $100 \mu \mathrm{g} /$ $\mathrm{ml})$ or SB203580 (10 nM; Calbiochem-Novabiochem Corp., San Diego, CA, USA) as described above for $48 \mathrm{~h}$. Protein concentrations of the cell lysates were determined by the bicinchoninic acid assay (BCA; Thermo Scientific, Rockford, IL, USA) and equal amounts of protein were loaded onto sodium dodecyl sulfate-polyacrylamide gel electrophoresis (SDS-PAGE), before being transferred to PVDF membranes (Millipore Corp., Bedford, MA, USA), and then processed according to the standard instructions. The antibodies used were rabbit anti-human phospho-p38 mitogen-activated protein kinase (p38-MAPK) (Thr180/Tyr182) monoclonal antibody (\#4631) and rabbit anti-p38-MAPK polyclonal antibody (\#9212) (both from Cell Signaling Technology); mouse anti-human cyclin D1 monoclonal antibody (sc20044), goat anti-COX-2 polyclonal antibody (sc23983), mouse anti-human Bcl-2 monoclonal antibody (sc509), rabbit anti-survivin polyclonal antibody (sc10811), mouse anti-human matrix metalloproteinase 9 (MMP-9) monoclonal antibody (sc21733), mouse anti-human intercellular adhesion molecule-1 (ICAM-1) monoclonal antibody (sc107), mouse anti-human vascular 
endothelial growth factor (VEGF) monoclonal antibody (sc7269) and rabbit anti- $\beta$-actin polyclonal antibody (sc130657) (dilution, 1:1,000) (all from Santa Cruz Biotechnology, Santa Cruz, CA, USA). The secondary antibodies were anti-rabbit or anti-mouse immunoglobulin $\mathrm{G}$ conjugated to horseradish peroxidase (dilution, 1:5,000; Beyotime). Signals were detected by enhanced chemiluminescence (ECL) reagent (Beyotime). The absorbance values of target proteins and data analysis were performed using Gel-Pro Analyzer version 4.0 software (Media Cybernetics, Silver Spring, MD, USA).

$N F-\kappa B$ assay. Cultured PC3 cells were seeded in 6-well plates at a density of $4 \times 10^{5}$ cells/well as indicated, respectively. Stimulation of LPS $(1 \mu \mathrm{g} / \mathrm{ml})$, sesamin $(100 \mu \mathrm{g} / \mathrm{ml})$ or SB203580 $(10 \mathrm{nM})$ was performed as described above after p38-siRNA/p38-siNS transfection or not. To prepare nuclear extracts for the NF- $\mathrm{kB}$ assay, the cells were washed with cold PBS, collected by centrifugation, resuspended in hypotonic lysis buffer, incubated on ice for $15 \mathrm{~min}$ and then mixed with $0.75 \%$ Nonidet P-40 (NP-40) solution. The nuclear extract was collected and centrifuged at $4,000 \mathrm{x}$ g for $2 \mathrm{~min}$, and stored at $-80^{\circ} \mathrm{C}$. Protein concentration was determined by the BCA assay. Then, NF- $\kappa \mathrm{B}$ activity in nuclear extracts was analyzed by a NF-кB p65 ActivELISA kit (Imgenex, San Diego, CA, USA) according to the manufacturer's instructions. The absorbance was determined using a microplate reader set at $405 \mathrm{~nm}$.

In vivo assay. Cultured PC3 cells were washed 3 times with PBS. For this, $1 \times 10^{7}$ cells $/ 100 \mu$ l PBS were inoculated subcutaneously at the right armpit of BALB/c nude mice. After 7 days, the mice were administered PBS (control) only, LPS $(2 \mathrm{mg} / \mathrm{kg})$ only or sesamin $(10 \mathrm{mg} / \mathrm{kg})$ and SB203580 $(10 \mathrm{mg} /$ $\mathrm{kg}$ ), respectively before injection with LPS ( $\mathrm{n}=4$ per group). The sesamin and SB203580 were injected every 3 days, respectively. Twenty-one days later, all mice from the different groups were sacrificed. Caliper measurement of tumor volume was conducted every other day, and the tumor volume $(\mathrm{V})$ was calculated according to the following formula: $\mathrm{V}=$ (largest diameter) $\mathrm{x}(\text { smallest diameter })^{2} / 2$.

Statistical analysis. Results are expressed as the mean \pm SD representative of three individual experiments performed in triplicate. Statistical analysis was performed by the Student's t-test and ANOVA test. $\mathrm{P}<0.05$ was considered to be statistically significant compared to the respective control.

\section{Results}

Sesamin inhibits LPS-induced cell proliferation. To examine whether sesamin modulates prostate cancer cell proliferation stimulated by LPS, we used the MTT assay and further investigated the effect of sesamin $(0,10,50$ and $100 \mu \mathrm{g} / \mathrm{ml})$ on the expression of proliferative-related proteins, cyclin D1 and COX-2, in the LPS-stimulated PC3 cells. We found that the proliferation rate of $\mathrm{PC} 3$ cells was distinctly promoted by LPS, but was distinctly suppressed by sesamin pretreatment in a dose- and time-dependent manner (Fig. 1A). Moreover, sesamin pretreatment dose-dependently downregulated the expression of cyclin D1 and COX-2 gene products induced by LPS (Fig. 1B and C). Therefore, sesamin had a negative

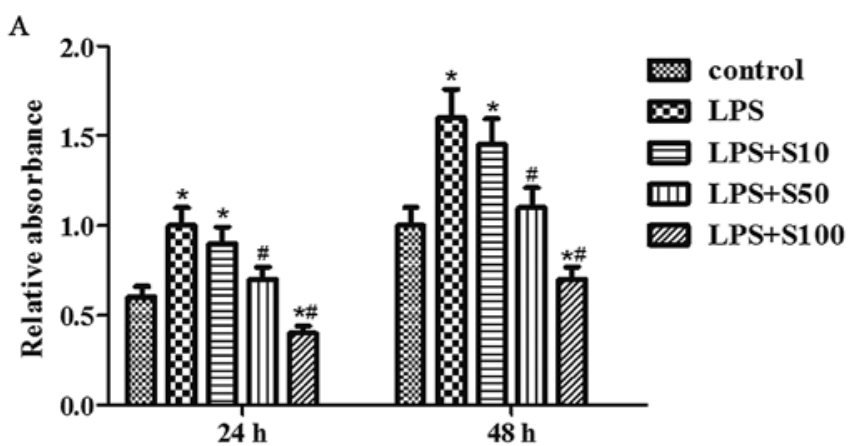

B
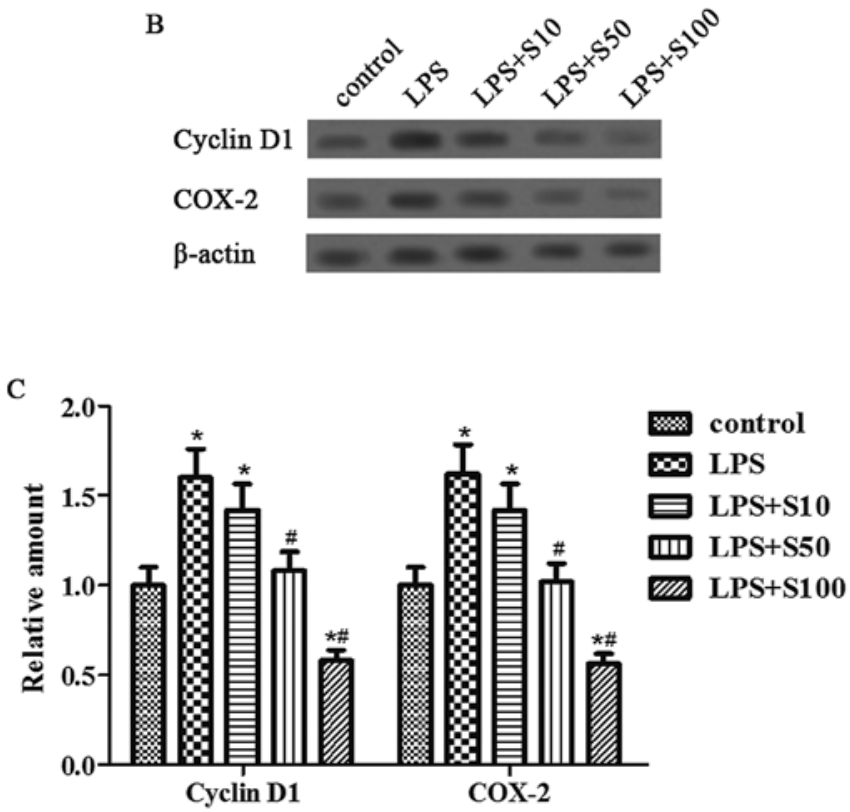

Figure 1. Sesamin suppresses prostate cancer cell proliferation induced by LPS. (A) PC3 cells were pre-incubated with sesamin of gradient concentrations prior to LPS stimulation as described in Materials and methods and stained using the MTT assay at 24 or $48 \mathrm{~h}$. The number of viable cells was determined via the absorbance. (B) PC3 cells were processed as described previously for $48 \mathrm{~h}$ and then harvested, and lysed. Cyclin D1, COX-2 and $\beta$-actin proteins were detected by western blotting. (C) Expression of cyclin D1 and COX-2 proteins was analyzed using Gel-Pro Analyzer version 4.0 software and normalized to $\beta$-actin. ${ }^{*} \mathrm{P}<0.05$, compared with control group. ${ }^{\text {}} \mathrm{P}<0.05$, compared with the LPS group. LPS, lipopolysaccharide.

effect on the cell proliferation and the expression of tumor cell-proliferative proteins induced by LPS in the PC 3 cells.

Sesamin inhibits the expression of $\mathrm{Bcl}-2$ and survivin proteins induced by LPS. To evaluate the effect of LPS and sesamin on prostate cancer cell apoptosis, we determined the expression of Bcl-2 and survivin proteins related to tumor cell survival with sesamin pretreatment under LPS stimulation. The results indicated that sesamin pretreatment dose-dependently inhibited the expression of Bcl-2 and survivin proteins induced by LPS (Fig. 2), thus implying that the possible mechanism for the anti-apoptotic effect of sesamin may be through the downregulation of cell survival proteins, including Bcl-2 and survivin.

Sesamin inhibits LPS-induced cell invasion. To determine the effect of LPS and sesamin on prostate cancer cell invasion, 
A
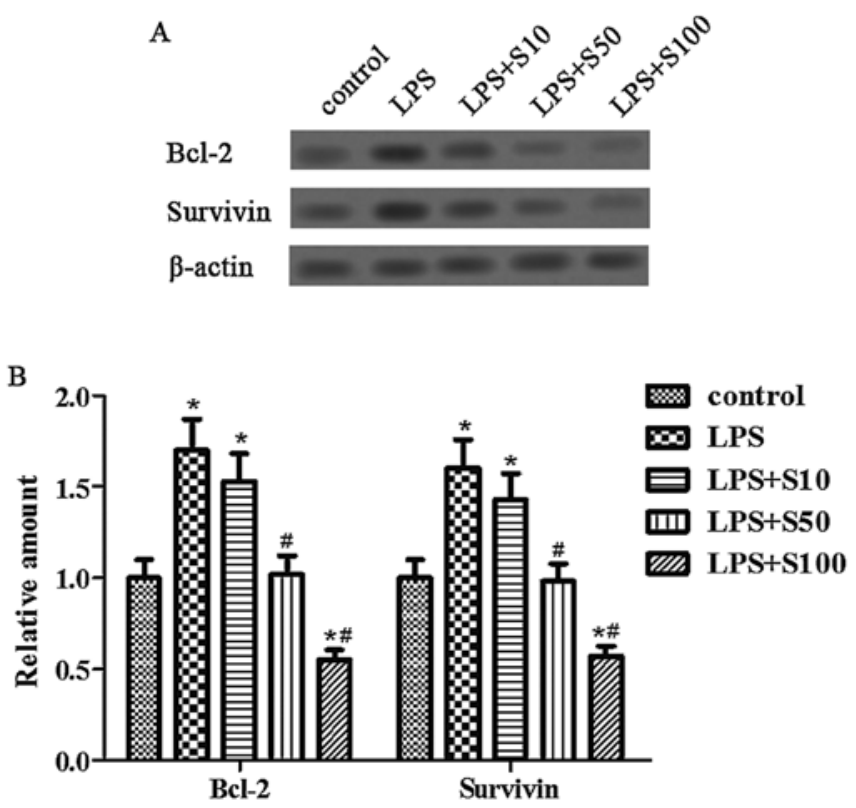

Figure 2. Sesamin downregulates the expression of Bcl-2 and survivin proteins induced by LPS. (A) PC3 cells were processed as described in Materials and methods for $48 \mathrm{~h}$; then, Bcl-2, survivin and $\beta$-actin proteins were detected by western blotting. (B) Expression of Bcl-2 and survivin proteins was analyzed using Gel-Pro Analyzer version 4.0 software and normalized to $\beta$-actin. " $\mathrm{P}<0.05$, compared with the control group. ${ }^{~} \mathrm{P}<0.05$, compared with the LPS group. LPS, lipopolysaccharide.

we used the Matrigel invasion assay and western blotting of invasion-related proteins, which are known to be involved in cancer cell invasion, adhesion and angiogenesis. The results revealed that the invasive ability of the PC 3 cells was markedly promoted by LPS and further markedly and dosedependently inhibited by sesamin pretreatment (Fig. 3A). More importantly, sesamin pretreatment dose-dependently suppressed the increased expression of MMP-9, ICAM-1 and VEGF proteins induced by LPS (Fig. 3B and C). Thus, these data confirmed the inhibitory role of sesamin in the invasiveness of prostate cancer and on the expression of tumor cell metastatic proteins.

Sesamin inhibits LPS-induced cytokine production. To investigate the effect of LPS and sesamin on the secretion of TGF- $\alpha$ and IL- 6 in PC3 cells, we detected the concentration of TGF- $\alpha$ and IL- 6 production in the culture supernatant of PC3 cells under LPS stimulation with sesamin pretreatment. The MTT assay revealed that there was no toxic impact on cells following these processes for $48 \mathrm{~h}$. The data revealed that the accumulation of TGF- $\alpha$ and IL- 6 production induced by LPS in conditioned medium was decreased dose-dependently following sesamin pretreatment in PC3 cells (Fig. 4).

Sesamin inhibits LPS-induced p38-MAPK activation. To examine whether the p38-MAPK signaling pathway is involved in the enhanced cell proliferation and invasion in response to TNF- $\alpha$ and IL- 6 accumulation, we detected the p-p38 and p38 proteins following either sesamin $(100 \mu \mathrm{g} / \mathrm{ml})$ or SB203580 $(10 \mathrm{nM})$ pretreatment or $\mathrm{p} 38$-siRNA/p38-siNS transfection in the LPS-stimulated PC3 cells. The results revealed that sesamin pretreatment inhibited the phosphorylation of the p38
A

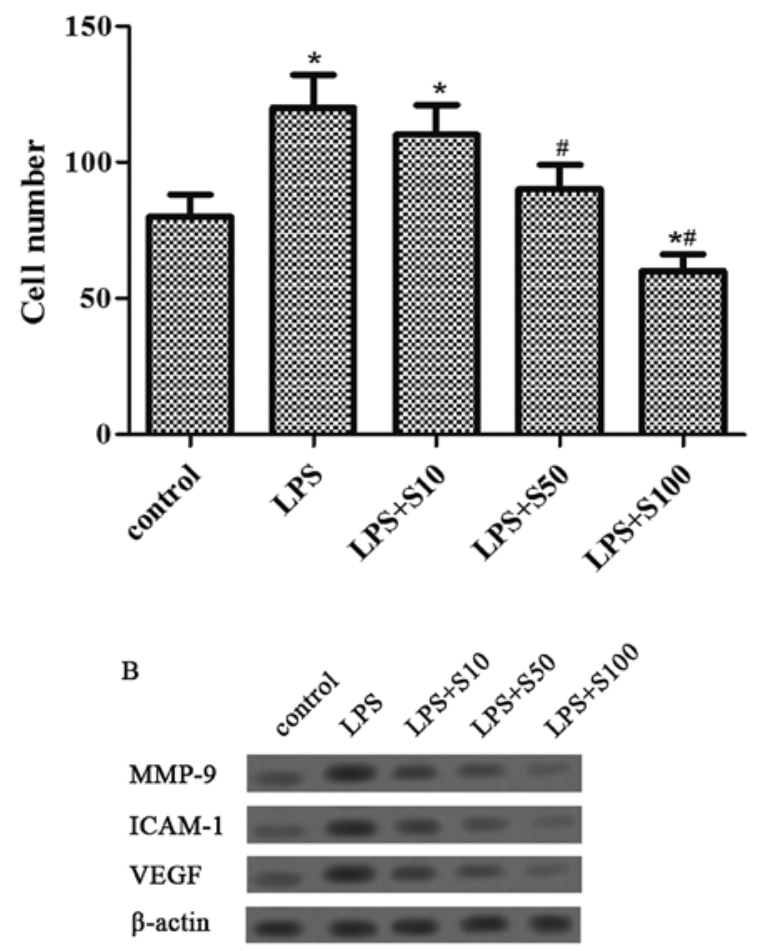

C

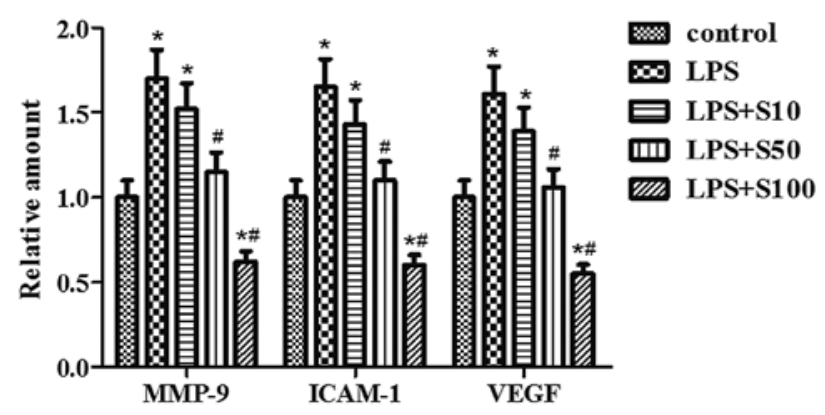

Figure 3. Sesamin attenuates cell invasion, as well as downregulates the expression of MMP-9, ICAM-1 and VEGF proteins induced by LPS. (A) PC3 cells were processed as described in Materials and methods for $48 \mathrm{~h}$ for the Transwell assay. The number of invasive cells was counted and analyzed statistically. (B) PC3 cells were processed as described in Materials and methods for $48 \mathrm{~h}$; then MMP-9, ICAM-1, VEGF and $\beta$-actin proteins were detected by western blotting. (C) Expression of MMP-9, ICAM-1 and VEGF proteins was analyzed using Gel-Pro Analyzer version 4.0 software and normalized to $\beta$-actin. " $\mathrm{P}<0.05$, compared with the control group. ${ }^{~} \mathrm{P}<0.05$, compared with the LPS group. LPS, lipopolysaccharide; MMP-9, matrix metalloproteinase 9; ICAM-1, intercellular adhesion molecule-1; VEGF, vascular endothelial growth factor.

protein increased by LPS stimulation, and pretreatment with SB203580, a specific inhibitor of p38-MAPK, showed the same degree of inhibition (Fig. 5A and B). In addition, compared to the control and $\mathrm{p} 38$-siNS transfection group, pretreatment with p38-siRNA transfection obviously decreased both p-p38 and p38 proteins under LPS stimulation.

Sesamin inhibits LPS-induced $N F-\kappa B$ activity. Importantly, to assess the effect of sesamin on NF- $\mathrm{KB}$ activity induced by LPS, we used SB203580 pretreatment or $\mathrm{p} 38$-siRNA/p38-siNS transfection to investigate the action mechanism of sesamin on NF- $\kappa B$ activity in the LPS-stimulated PC3 cells. Similar 


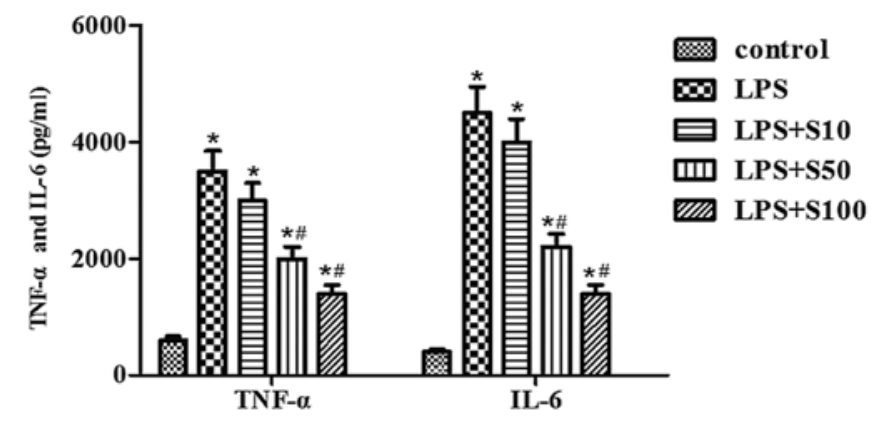

Figure 4. Sesamin inhibits LPS-induced TGF- $\alpha$ and IL-6 production in the PC 3 cells. PC 3 cells were processed as described in Materials and methods and the culture supernatant was collected over $48 \mathrm{~h}$ for TNF- $\alpha$ and IL- 6 concentration detection using an ELISA kit. ${ }^{*} \mathrm{P}<0.05$, compared with the control group. ${ }^{*} \mathrm{P}<0.05$, compared with the LPS group. LPS, lipopolysaccharide; TNF- $\alpha$, tumor necrosis factor- $\alpha$; IL-6, interleukin-6.
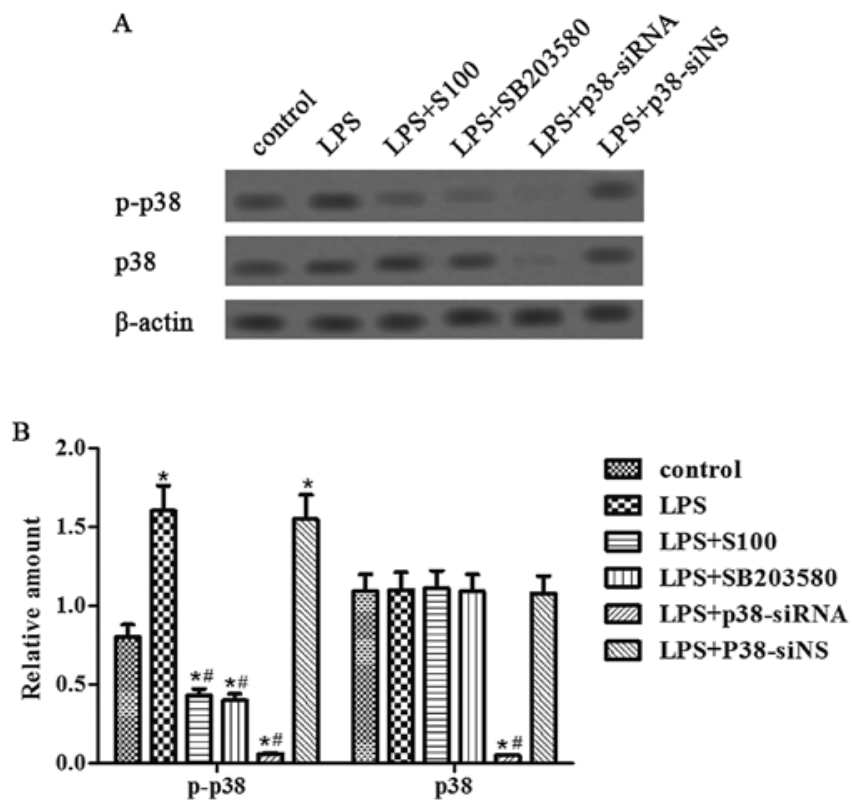

Figure 5. Sesamin attenuates the phosphorylation of p38 protein induced by LPS. (A) PC3 cells transfected with or without p38-siRNA/p38-siNS were processed as described in Materials and methods for $48 \mathrm{~h}$. Then p-p38, p38 and $\beta$-actin proteins were detected by western blotting. (B) Expression of p-p38 and p38 proteins was analyzed using Gel-Pro Analyzer version 4.0 software and normalized to $\beta$-actin. ${ }^{*} \mathrm{P}<0.05$, compared with the control group. ${ }^{\#} \mathrm{P}<0.05$, compared with the LPS group. LPS, lipopolysaccharide.

to the inhibitory effect of SB203580 and p38-siRNA, sesamin pretreatment clearly suppressed the constitutive and inducible NF- $\kappa \mathrm{B}$ activity at a concentration of $100 \mu \mathrm{g} / \mathrm{ml}$ (Fig. 6). Therefore, it can be concluded that LPS-induced translocation of the NF- $\mathrm{KB}$ p65 subunit to the nucleus could be inhibited by sesamin to some extent.

Sesamin reduces $P C 3$ cell-derived tumor growth enhanced by $L P S$ in vivo. To evaluate the effect of sesamin on tumor growth in vivo, we used the SB203580 pretreatment to determine the LPS-stimulated tumor progression derived from PC3 cells in $\mathrm{BALB} / \mathrm{c}$ nude mice. Compared to the control group, the tumor volume in the LPS pretreatment group was distinctly larger, and the tumor volume in the LPS plus sesamin group

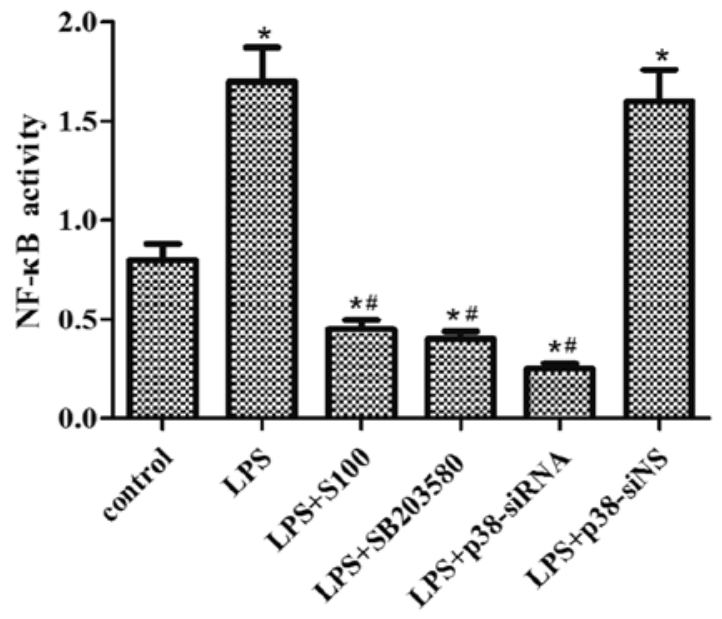

Figure 6. Sesamin suppresses NF- $\mathrm{NB}$ activity induced by LPS. PC3 cells transfected with or without $\mathrm{p} 38$-siRNA/p38-siNS were processed as described in Materials and methods for $48 \mathrm{~h}$. The NF- $\kappa \mathrm{B}$ activity was detected by a NF- $\kappa \mathrm{B}$ p65 ActivELISA kit. ${ }^{*} \mathrm{P}<0.05$, compared with the control group. ${ }^{\#} \mathrm{P}<0.05$, compared with the LPS group. LPS, lipopolysaccharide; $\mathrm{NF}-\kappa \mathrm{B}$, nuclear factor $\kappa \mathrm{B}$.

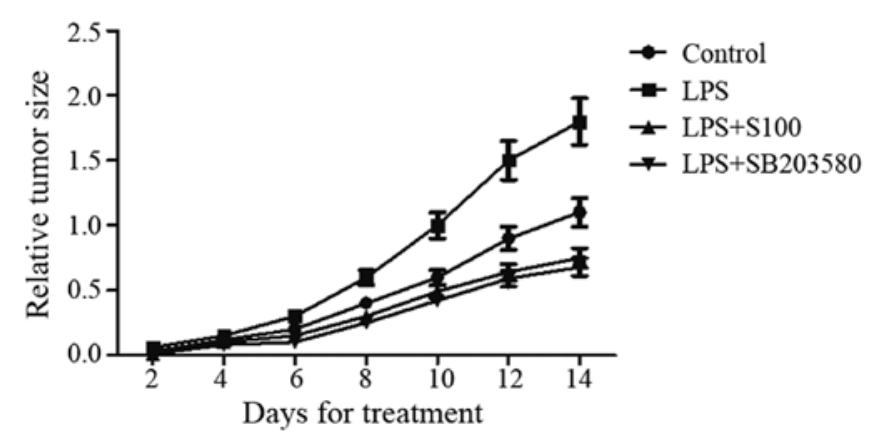

Figure 7. Sesamin suppresses tumor growth stimulated by LPS in tumor-bearing mice. PC3 cells were inoculated into BALB/c nude mice and the mice were grouped according to the various treatments. SB203580 or sesamin injection was performed prior to LPS treatment as described in Materials and methods. Tumor volumes were measured every other day and recorded for analysis. LPS, lipopolysaccharide.

was relatively smaller after 14 days post-incubation (Fig. 7). The results illustrated that either sesamin or SB203580 treatment could obviously inhibit PC3 cell-derived tumor growth induced by LPS in vivo.

\section{Discussion}

Prostate cancer is a relatively common cancer among males worldwide, and an increasing number of men are at a high risk due to various reasons, including dietary and environmental factors. Sesamin, a type of phytoestrogen, is a lignan that is found abundantly in sesame oil and potentially possesses multiple functions, such as antioxidant, anti-inflammatory, and anticancer activities. Considering this, the present study mainly focused on the protective effect of sesamin on the development of prostate cancer cell invasion and tumor progression under LPS stimulation.

Research has shown that sesamin induces arrest at the G1 phase of the cell cycle in human breast cancer MCF-7 
cells (26) and inhibits cell proliferation in various types of tumor cells (29). Sesamin also suppresses TNF-induced expression of cyclin D1, COX-2 and cell survival gene products including Bcl-2 and survivin proteins in human chronic myeloid leukemia cells (29). In addition, the COX-2 protein is reported to be overexpressed in lung tumor tissues (30) and the inhibition of COX-2 can arrest progression of the cell cycle in prostate cancer cells (31). In addition, LPS promotes cell survival and proliferation in hepatocellular carcinoma cells (32) and significantly activates the expression and activity of COX-2 in human colon carcinoma cells (33). In the present study, our data indicated that sesamin pretreatment suppressed LPS-induced PC 3 cell proliferation and the expression of cyclin D1, COX-2, Bcl-2 and survivin proteins, which are correlated with cell proliferation, the synthesis and secretion of prostaglandin E2 and cell survival.

Moreover, sesamin was previously found to inhibit the levels of TNF- $\alpha$ and IL-6 induced by macrophages, and reduced the expression of VEGF and MMP-9 proteins, thus suppressing cell migration and exhibiting anti-angiogenic activity in human breast cancer MCF-7 cells (34). Our results revealed that the accumulation of TNF- $\alpha$ and IL- 6 was enhanced by LPS and was suppressed to a lesser degree by sesamin pretreatment in a dose-dependent manner in PC3 cells. Furthermore, sesamin also showed a distinct negative effect on LPS-induced PC3 cell invasion and the expression of MMP-9, ICAM-1 and VEGF proteins, thus implying the potential role of sesamin in the suppression of human prostate cancer cell invasion, adhesion and the prevention of tumor angiogenesis. Hence, we conclude that sesamin downregulates the abnormal induction of related inflammatory cytokines such as TNF- $\alpha$ and IL-6 induced by LPS, and in turn, inhibits the reinforced induction of proteins which are associated with cell invasion and progression in prostate cancer PC 3 cells.

In addition, an abnormality in levels of these cytokines has also been shown as one of the major causes of constitutive p38-MAPK signaling pathway and NF- $\mathrm{KB}$ activity in cancer cells $(34,35)$. Meanwhile, LPS cytotoxicity is reported to be mediated through the activation of p38-MAPK and NF- $\mathrm{kB}$ pathways in hepatocellular carcinoma cells (32). Upon LPS stimulation, the phosphorylation of p38 was detected in human esophageal cancer cells (36). NF- $\mathrm{KB}$ activity has been commonly associated with inflammation, carcinogenesis, tumor cell survival, proliferation, invasion and angiogenesis of cancer (29). More importantly, both nuclear levels of NF- $\mathrm{KB}$ and p38-MAPK activity were found to be potently inhibited by sesamin via the downregulation of TNF- $\alpha$ and IL- 6 in human breast cancer cells (34). Likewise, our research found that sesamin significantly suppressed phosphorylation of the p38 protein and the NF- $\mathrm{kB}$ activity induced by LPS in prostate cancer PC3 cells.

Furthermore, SB203580, a specific inhibitor of p38-MAPK, specifically reduces cell proliferation, migration and survival in prostate cancer cells (37), and SB203580 pretreatment of head and neck squamous cell carcinoma cells also reduced cancer growth in tumor xenografts (38). Mice treated with chronic inhibition of p38-MAPK with SB203580 showed complete absence of osteoblastic growth in the intramedullary space as well as significantly reduced tumor burden (39). In the present study, we used a nude mouse model to investigate the role of the p38-MAPK and NF- $\kappa B$ signaling pathways activated by LPS on inflammation-induced tumor growth by an in vivo assay. Consistently, our research showed that tumor growth was distinctly enhanced in response to LPS and further significantly restrained by sesamin or SB203580 pretreatment in terms of tumor size. In addition, sesamin or SB203580 pretreatment led to distinct reductions in the phosphorylation of $\mathrm{p} 38$ protein and NF- $\mathrm{KB}$ activity induced by LPS. Meanwhile, cells transfected with p38-siRNA showed the same inhibitory effect, implying the potential role of the p38-MAPK and NF- $\mathrm{KB}$ pathways in the sesamin-pretreated $\mathrm{PC} 3$ cells.

Collectively, these results demonstrated that sesamin significantly attenuated the expression of TNF- $\alpha$, IL-6, cyclin D1, COX-2, Bcl-2 and survivin, as well as MMP-9, ICAM-1 and VEGF proteins induced by LPS through the p38-MAPK signaling pathway and NF- $\mathrm{KB}$ activation in PC3 cells under LPS stimulation and further inhibited tumor growth in tumors derived from the inoculation of PC 3 cells. Thus, the present study showed the suppressive activity of sesamin on prostate cancer cell proliferation and invasion induced by LPS. These findings may assist in the better understanding of the molecular mechanisms of the effects of sesamin on cell invasiveness and tumorigenesis, thus providing a new insight into the effect of sesamin during the progression of human prostate cancer.

\section{References}

1. Lin SS, Clarke CA, Prehn AW, Glaser SL, West DW and O'Malley CD: Survival differences among Asian subpopulations in the United States after prostate, colorectal, breast, and cervical carcinomas. Cancer 94: 1175-1182, 2002.

2. Hsing AW, Tsao L and Devesa SS: International trends and patterns of prostate cancer incidence and mortality. Int $\mathrm{J}$ Cancer 85: 60-67, 2000.

3. Hsing AW and Devesa SS: Trends and patterns of prostate cancer: what do they suggest? Epidemiol Rev 23: 3-13, 2001.

4. Sonn GA, Aronson W and Litwin MS: Impact of diet on prostate cancer: a review. Prostate Cancer Prostatic Dis 8: 304-310, 2005.

5. Schetter AJ, Heegaard NH and Harris CC: Inflammation and cancer: interweaving microRNA, free radical, cytokine and p53 pathways. Carcinogenesis 31: 37-49, 2010.

6. Coussens LM and Werb Z: Inflammation and cancer. Nature 420: 860-867, 2002.

7. Mantovani A: Cancer: inflammation by remote control. Nature 435: 752-753, 2005.

8. Hsu RY, Chan CH, Spicer JD, Rousseau MC, Giannias B, Rousseau S and Ferri LE: LPS-induced TLR4 signaling in human colorectal cancer cells increases betal integrin-mediated cell adhesion and liver metastasis. Cancer Res 71: 1989-1998, 2011.

9. Li J, Chong T, Wang Z, Chen H, Li H, Cao J, Zhang P and Li H: A novel anti-cancer effect of resveratrol: reversal of epithelial mesenchymal transition in prostate cancer cells. Mol Med Rep 10: 1717-1724, 2014.

10. Im HJ, Park NH, Kwon YJ, Shin S, Kim D and Chun YJ: Bacterial lipopolysaccharides induce steroid sulfatase expression and cell migration through IL-6 pathway in human prostate cancer cells. Biomol Ther (Seoul) 20: 556-561, 2012.

11. Michalaki V, Syrigos K, Charles P and Waxman J: Serum levels of IL-6 and TNF-alpha correlate with clinicopathological features and patient survival in patients with prostate cancer. $\mathrm{Br}$ J Cancer 90: 2312-2316, 2004.

12. Balkwill F: Tumor necrosis factor or tumor promoting factor? Cytokine Growth Factor Rev 13: 135-141, 2002.

13. Szlosarek PW and Balkwill FR: Tumour necrosis factor alpha: a potential target for the therapy of solid tumours. Lancet Oncol 4: 565-573, 2003.

14. Ayre JE: Cervical cancer: chronic inflammation, stress and adaptation factors. Acta Unio Int Contra Cancrum 12: 20-27, 1956. 
15. Dalgleish AG and O'Byrne KJ: Chronic immune activation and inflammation in the pathogenesis of AIDS and cancer. Adv Cancer Res 84: 231-276, 2002.

16. Farrow B and Evers BM: Inflammation and the development of pancreatic cancer. Surg Oncol 10: 153-169, 2002.

17. Nelson WG, De Marzo AM, DeWeese TL and Isaacs WB: The role of inflammation in the pathogenesis of prostate cancer. $\mathrm{J}$ Urol 172: S6-S12, 2004

18. Schwartsburd PM: Chronic inflammation as inductor of pro-cancer microenvironment: pathogenesis of dysregulated feedback control. Cancer Metastasis Rev 22: 95-102, 2003.

19. Tiwari N, Gheldof A, Tatari M and Christofori G: EMT as the ultimate survival mechanism of cancer cells. Semin Cancer Biol 22: 194-207, 2012.

20. Chen MC, Chang WW, Kuan YD, Lin ST, Hsu HC and Lee CH: Resveratrol inhibits LPS-induced epithelial-mesenchymal transition in mouse melanoma model. Innate Immun 18: 685-693, 2012.

21. Lu JN, Lee WS, Kim MJ, Yun JW, Jung JH, Yi SM, Jeong JH, Kim HJ, Choi YH, Kim GS, et al: The inhibitory effect of anthocyanins on Akt on invasion and epithelial-mesenchymal transition is not associated with the anti-EGFR effect of the anthocyanins. Int J Oncol 44: 1756-1766, 2014.

22. Yang CS and Wang X: Green tea and cancer prevention. Nutr Cancer 62: 931-937, 2010

23. Gloria NF, Soares N, Brand C, Oliveira FL, Borojevic R and Teodoro AJ: Lycopene and beta-carotene induce cell-cycle arrest and apoptosis in human breast cancer cell lines. Anticancer Res 34: 1377-1386, 2014

24. Akl MR, Ayoub NM, Abuasal BS, Kaddoumi A and Sylvester PW: Sesamin synergistically potentiates the anticancer effects of $\gamma$-tocotrienol in mammary cancer cell lines. Fitoterapia 84 347-359, 2013.

25. Tanabe H, Kuribayashi K, Tsuji N, Tanaka M, Kobayashi D and Watanabe N: Sesamin induces autophagy in colon cancer cells by reducing tyrosine phosphorylation of EphA1 and EphB2. Int J Oncol 39: 33-40, 2011.

26. Yokota T, Matsuzaki Y, Koyama M, Hitomi T, Kawanaka M, Enoki-Konishi M, Okuyama Y, Takayasu J, Nishino H, Nishikawa A, et al: Sesamin, a lignan of sesame, down-regulates cyclin D1 protein expression in human tumor cells. Cancer Sci 98: 1447-1453, 2007.

27. Deng P, Wang C, Chen L, Wang C, Du Y, Yan X, Chen M, Yang G and $\mathrm{He} \mathrm{G}$ : Sesamin induces cell cycle arrest and apoptosis through the inhibition of signal transducer and activator of transcription 3 signalling in human hepatocellular carcinoma cell line HepG2. Biol Pharm Bull 36: 1540-1548, 2013.

28. Wang HM, Cheng KC, Lin CJ, Hsu SW, Fang WC, Hsu TF, Chiu CC, Chang HW, Hsu CH and Lee AY: Obtusilactone A and (-)-sesamin induce apoptosis in human lung cancer cells by inhibiting mitochondrial Lon protease and activating DNA damage checkpoints. Cancer Sci 101: 2612-2620, 2010.
29. Harikumar KB, Sung B, Tharakan ST, Pandey MK, Joy B, Guha S, Krishnan S and Aggarwal BB: Sesamin manifests chemopreventive effects through the suppression of NF-kappa B-regulated cell survival, proliferation, invasion, and angiogenic gene products. Mol Cancer Res 8: 751-761, 2010.

30. Liu L, Ge D, Ma L, Mei J, Liu S, Zhang Q, Ren F, Liao H, Pu Q, Wang T, et al: Interleukin-17 and prostaglandin E2 are involved in formation of an M2 macrophage-dominant microenvironment in lung cancer. J Thorac Oncol 7: 1091-1100, 2012.

31. Bieniek J, Childress C, Swatski MD and Yang W: COX-2 inhibitors arrest prostate cancer cell cycle progression by down-regulation of kinetochore/centromere proteins. Prostate 74: 999-1011, 2014.

32. Wang L, Zhu R, Huang Z, Li H and Zhu H: Lipopolysaccharide-induced toll-like receptor 4 signaling in cancer cells promotes cell survival and proliferation in hepatocellular carcinoma. Dig Dis Sci 58: 2223-2236, 2013.

33. Li Y, Fan L, Sun Y, Zhang D, Yue Z, Niu Y, Meng J, Yang T, Liu W and Mei Q: An apple oligogalactan suppresses endotoxin-induced cyclooxygenase-2 expression by inhibition of LPS pathways. Int J Biol Macromol 61: 75-81, 2013.

34. Lee CC, Liu KJ, Wu YC, Lin SJ, Chang CC and Huang TS: Sesamin inhibits macrophage-induced vascular endothelial growth factor and matrix metalloproteinase-9 expression and proangiogenic activity in breast cancer cells. Inflammation 34: 209-221, 2011.

35. Lu T and Stark GR: Cytokine overexpression and constitutive NFkappaB in cancer. Cell Cycle 3: 1114-1117, 2004.

36. Rousseau MC, Hsu RY, Spicer JD, McDonald B, Chan $\mathrm{CH}$, Perera RM, Giannias B, Chow SC, Rousseau S, Law S, et al: Lipopolysaccharide-induced toll-like receptor 4 signaling enhances the migratory ability of human esophageal cancer cells in a selectin-dependent manner. Surgery 154: 69-77, 2013.

37. Zhang Y, Guo Z, Du T, Chen J, Wang W, Xu K, Lin T and Huang $\mathrm{H}$ : Prostate specific membrane antigen (PSMA): a novel modulator of $\mathrm{p} 38$ for proliferation, migration, and survival in prostate cancer cells. Prostate 73: 835-841, 2013.

38. Leelahavanichkul K, Amornphimoltham P, Molinolo AA, Basile JR, Koontongkaew S and Gutkind JS: A role for p38 MAPK in head and neck cancer cell growth and tumor-induced angiogenesis and lymphangiogenesis. Mol Oncol 8: 105-118, 2014.

39. Sukhtankar D, Okun A, Chandramouli A, Nelson MA, Vanderah TW, Cress AE, Porreca F and King T: Inhibition of p38-MAPK signaling pathway attenuates breast cancer induced bone pain and disease progression in a murine model of cancer-induced bone pain. Mol Pain 7: 81, 2011. 